\section{O saber local e os dilemas relacionados à validação e aplicabilidade do conhecimento científico em áreas rurais}

\author{
Local knowledge and dilemmas related to \\ validity and applicability of scientific knowledge \\ in rural areas
}

Brani Rozemberg 1

\section{Introdução}

Based on previous experience from two research projects on schistosomiasis in rural populations, this article focuses on the relations between scientific health knowledge and health-related common sense in farming communities. The article discusses factors that affect the meaning of participation by these communities in exogenous programs, as well as the dilemmas related to the appropriation, validity, and applicability of multiple and non-contextualized health information offered by such programs. The article discusses how the acritical aggregation of large amounts of information, a feature of globalization, deepens the feeling of uncertainty in rural communities and the trend to impute diseases to fatality. Meanwhile, the consumption of medical technologies is viewed as a symbol of progress and is highly valued by these groups. The discussion addresses the important role of health personnel in valuing local empirical knowledge, fostering the incorporation of useful technical knowledge without compromising the cultural heritage on which the identity and health of such groups are based.

Rural Population; Health Communication; Public Perception of Science
Os historiadores de ciência ressaltam como o conhecimento científico foi mantido por séculos distante da sociedade pelos próprios cientistas, para resguardar seu status social; a ciência sedimentou-se longe da sociedade, guardando a história das idéias científicas uma enorme distância da sociologia do comportamento coletivo ${ }^{1}$.

Foi justamente graças a esse paradigma que nos acostumamos a excluir do esforço de compreender as doenças infecciosas, todo o acúmulo de conhecimentos, de caráter empírico, existente na memória coletiva das populações mais vulneráveis a elas expostas.

Em anos recentes e, em conformidade com os pressupostos do campo da Promoção da Saúde, é crescente, nos meios acadêmicos, a compreensão da saúde e doença como produções sociais e culturais, inseparáveis do acervo de conhecimentos construído e partilhado em nível local. A lógica do senso comum de populações expostas às doenças estudadas, e o universo de experiências concretas e práticas sociais, antes marginalmente considerados, passam a ter lugar nas análises, como previa o filósofo Boaventura Souza Santos 2 ao destacar o lugar do senso comum na ciência pós-moderna. Aquela antiga constatação de Marcel Mauss (1925, apud Geertz $\left.{ }^{3}\right)$ de que a prece e o direito não existem e sim o melanésio de tal ou qual ilha (posto que é este quem coloca em movimento a prece ou o direito 
no mundo), finalmente parece estar sendo alcançada pelo pensamento acadêmico.

Entretanto, o reconhecimento da relevância da condição social e subjetiva das populações expostas, ainda que venha ganhando espaço na produção acadêmica, parece não estar chegando com a mesma intensidade ao exercício concreto da educação e das ações nos serviços de saúde em áreas endêmicas, que ainda se dá nos moldes cognitivistas e behavioristas, integrando pouco os determinantes culturais de saúde e doença e atropelando-os sumariamente na consecução de suas agendas, centradas na transmissão do saber técnico/científico e de sua própria lógica e racionalidade.

Tal abismo entre teoria e prática resulta em parte de uma tendência (generalizada nas sociedades contemporâneas ${ }^{4}$ ), de supervalorização dos conhecimentos construídos no sistema socialmente reconhecido de instituições acadêmicas; e em parte da dificuldade em se compreender e problematizar de maneira crítica e aberta a sua relação com os valores e decisões tomadas em contextos sócio-culturais distintos.

Assim, se as condições que associam senso comum e conhecimento científico parecem estar se modificando, devido a novas posturas da comunidade científica 5, tais aproximações são insuficientes para se falar em integração, o que se constitui em um desafio, pois representa uma forma nova de "iluminar a realidade" a nos exigir bem mais, porque requer uma mudança na posição dos refletores 6 .

As questões às quais nos dedicaremos no presente texto resultam de quase uma década de entrevistas com moradores de áreas endêmicas para a esquistossomose. Foram ao todo 153 entrevistas em dois projetos distintos em uma variedade de contextos ecológicos, culturais e econômicos em que ocorre a transmissão da esquistossomose nas regiões Nordeste e Sudeste do Brasil. O primeiro projeto levantava dados para a realização de um vídeo com populações rurais dedicadas à atividade agrícola em área endêmica 7, enquanto o segundo avaliava esse material em áreas do Sudeste e Nordeste 8 .

As questões em foco também emergem da experiência nos últimos seis anos com moradores de uma aldeia agrícola de Nova Friburgo, Rio de Janeiro, Brasil. Como representantes do meio acadêmico, realizando pesquisas, tivemos a oportunidade de analisar repercussões da atuação de serviços locais, da implementação de ONG e de iniciativas governamentais, na experiência rural em saúde, endemias, saneamento e outras temáticas. Tais pesquisas em Nova Friburgo 9,10,11, somadas à experiência de contínua imersão no senso comum de uma comunidade rural, aprofundaram nossas inquietações sobre a relação entre racionalidade científica e aquela partilhada em contextos rurais.

No presente texto, propomos uma reflexão sobre a validação, apropriação e aplicabilidade do saber técnico-científico na experiência rural em saúde, ilustrada por meio de exemplos de campo. Nossa contribuição ao debate sobre desigualdade, globalização e ressurgência das doenças infecciosas na América Latina é indireta, posto que restrita a analisar repercussões no nível local de uma das facetas da globalização, qual seja, o fenômeno, em escala global, de contínua produção e atualização de conhecimentos científicos e de uso e substituição de tecnologias deles decorrentes.

A idéia é subsidiar ações de intervenção em contextos rurais, como é o caso dos programas de prevenção e controle de doenças infecciosas, para um posicionamento crítico em relação ao seu papel na difusão de conhecimentos.

Finalmente, o fato de estarmos trabalhando junto com populações rurais, temáticas outras que não as endemias, nos permite uma saudável modificação na posição dos refletores, permitindo olhar tais grupos não apenas pelo ângulo de sua vulnerabilidade a processos mórbidos, mas também em sua relação com outros elementos de seu meio ambiente e no jogo de relações envolvidas na construção de sua identidade.

\section{O nível local como centro do mundo e o \\ resto do planeta como periferia}

Assim como para os agricultores prevalece ainda a convicção inabalável de que é o sol quem gira em torno da terra todos os dias (e de fato é assim que vivenciamos este fato no senso comum), também prevalece a certeza de que o resto do mundo gira perifericamente em torno da vida de sua comunidade, de seu contexto local definido e das adjacências até onde a vista alcança. É preciso levar em conta, que cerca de $40 \%$ dos entrevistados de nossas pesquisas jamais sequer deixaram a propriedade onde nasceram. Aqueles que mudaram de residência, em geral, fizeramno para as redondezas e no máximo para algum outro município próximo. Entre os habitantes rurais, a experiência de ter ido a algum outro Estado do Brasil é raríssima. Eventualmente, caravanas católicas para a cidade de Aparecida, São Paulo ou outro ponto de reunião religiosa deslocam agricultores por horas e horas de ônibus para uma permanência de um ou dois dias, mas sempre mantendo uma sólida agregação e proteção interna do grupo de viajantes que evita sempre falar com estranhos. 
Assim, para que o educador ou qualquer profissional que exerça ações de intervenção em áreas rurais possa trabalhar a noção de local e de lugar com tais grupos, é necessário considerar que pouco se deslocam e que não foram expostos ao processo de escolarização que lhes forneceria rudimentos de informação geográfica.

É humano considerar o que está próximo como referência, mas na ausência de tais rudimentos de referencial geográfico a compreensão do nível local como o centro do mundo torna-se inequívoca. Exemplificamos essa tendência com o seguinte episódio. Quando o representante de uma ONG ambientalista reuniu a comunidade, afirmava que com as ações por ele propostas a comunidade iria passar a ser conhecida, iria "entrar no mapa". Falava, entusiasmado, sobre as potencialidades locais para agroecologia. Entretanto, a reação da comunidade às suas palavras foi de total estranhamento, e os comentários em ocasiões posteriores eram no sentido de que o palestrante devia ter problemas mentais. Compreendemos, aos poucos, que em nenhum momento de sua existência a comunidade se via "fora do mapa" até porque, sem saber ler, e sem ter visto um mapa, são eles mesmos os únicos a existirem no território, o lugar onde se vive desde a infância, onde se trabalha, o cenário único de todas as histórias de vida locais, local cercado de imensidão de floresta onde se está irremediavelmente inserido até a morte. É importante esclarecer que, do ponto de vista desses grupos, quem está em posição periférica são as demais pessoas, tratadas genericamente como "gente de fora".

Essa constatação é importante para quem pretende trabalhar com participação comunitária, pois modifica radicalmente a posição dos refletores sobre a noção de participação. Afinal, quando as comunidades rurais não aderem a um programa de prevenção ou controle de endemias, quem efetivamente não está participando? E de quê?

Quando aportamos em campo com nossas propostas e programas, somos vistos como uns poucos indivíduos de "fora" desenraizados, nômades, sem história, sem sobrenome, sem pertencimento às famílias locais (literalmente uns pobres coitados por falta desses referenciais básicos de identidade rural), apresentando como símbolo de pertencimento siglas institucionais, sem significado algum nas comunidades (FIOCRUZ etc.).

Aportamos nas comunidades rurais com uma perspectiva etnocêntrica, com propostas de promoção e prevenção construídas unilateralmente no interior de uma cultura acadêmica que não leva em conta a intensa e dinâmica experiência de participação local diária em seus próprios assuntos de saúde e doença. Por outro lado, em nossa perspectiva do conhecimento, quase sempre lançamos mão de inúmeros outros referenciais sócio-geográficos, bem como de exemplos e eventos de natureza global para explicar os fenômenos. Tais generalizações e abstrações, por vezes, carecem totalmente de consistência lógica para os grupos rurais $8,11,12$.

E concluímos em nossos relatórios que o nível de participação foi baixo, ou que as comunidades não aderem ou não se integram a tal ou qual programa, usando terminologias como "excluídos" e "marginalizados", tomando como referência, a sociedade nacional mais abrangente ou a comunidade global.

Contudo, em áreas rurais, noções clássicas de centro e periferia nem sempre fazem sentido, e a idéia de si mesmo e de seu grupo comunitário em uma posição marginal soa bizarra na maior parte das comunidades rurais onde trabalhamos. Não que a pobreza, a miséria, e a noção de desigualdade social e de indigência em relação a serviços de "gente de fora" esteja alienada do pensamento dos grupos. Não se trata de negar esse nível de realidade, ou de afirmar que tais grupos - especialmente aqueles a que a televisão já chegou - desconheçam que existe uma sociedade mais abrangente onde circulam capital, mercadorias e serviços em larga escala. Sabem, inclusive, da sua posição inferior na escala social. Essas noções têm o seu lugar e estão presentes nos discursos. Mas, nas sociedades rurais estruturadas em torno do trabalho, da família e da comunidade, com raros aportes de "gente de fora", sem noções de geografia global, ou de escala demográfica, não circula no senso comum a idéia de estarem na periferia de alguma outra sociedade, pelo contrário, o seu referencial identitário constitui o centro do mundo, do qual participam ativamente.

Tal mudança na posição dos refletores sobre o tema da "participação" foi expressa por um entrevistado ao tecer o seguinte comentário a respeito de determinado programa oficial: "É uma pena que atualmente eles estão participando muito pouco. Eles teriam que vir, que participar mais". Essa inversão da idéia de participação coloca o foco na vida local e os técnicos no lugar de exclusão. Afirma que os programas estão marginalizados das práticas sociais locais, dos processos locais de saúde e doença, como vimos, os únicos com existência concreta "no mapa". O resto, voltando a célebre frase de Mauss (1925, apud Geertz 3) são as preces sem os melanésios, conjunto de propostas exógenas pensadas para um outro que não consultado sobre a matéria, por vezes toma-a por estultice ou insanidade.

Essa incompreensão mútua dos significados e motivações entre técnicos e população é 
exemplificada por um episódio ocorrido em área endêmica do Espírito Santo. Após uma longa entrevista em que o entrevistado descreveu perfeitamente o ciclo de transmissão da esquistossomose, a viatura que nos conduzia em campo quebrou e fomos obrigados a pernoitar na casa do entrevistado. No dia seguinte, conhecendo-nos um pouco mais, ele, subitamente, nos deu um cúmplice tapinha no ombro e desabafou: "Que estória aquilo que eu te contei ontem, hein?!". Perguntamos: “Como assim?” “Ah, aquela estória do caramujo entrar na pele de uma pessoa! Imagina se pode uma lesma mole daquela furar o couro duro de um pé de um homem!". Revelava que aquilo que disse na entrevista do dia anterior era parte de um ritual que o saber sanitário, por alguma razão, insiste em que seja repetido, mas que a vida real e a experiência não confirmam. Agora, mais à vontade, podia expressar a sua verdade local sobre a esquistossomose.

Esse episódio revela que a repetição de informações exógenas, não torna automática a substituição dos significados construídos pela experiência de vida e pela partilha cotidiana dos conhecimentos do senso comum. A experiência é que pode oferecer evidências definitivas, consolidar novas verdades e modificar conceitos, práticas e comportamentos, que se revelem de interesse para a saúde em seu sentido mais abrangente (para a vida).

Todavia, do ponto de vista das práticas dos programas de saúde, parece não ter ocorrido ainda um reconhecimento formal, oficial, de que apesar de se ocuparem aparentemente da mesma temática, profissionais e clientela são núcleos discursivamente distintos, elaborando significados segundo experiências e mundos identitários próprios 13 . Tudo se passa como se a transmissão de informações fosse suficiente para gerar mudanças de perspectiva e melhores escolhas em saúde.

E, finalmente, um último episódio confirmando a consolidação de saberes com base na experiência concreta no nível local. No pensamento dos grupos rurais de Nova Friburgo, as águas estão diminuindo de quantidade nos córregos devido ao reflorestamento, o que representa uma inversão em relação aos conhecimentos científicos disponíveis no campo da ecologia. Ao discutir, na beira de um córrego, a escassez das águas, usamos o argumento de que existem estudos comprovando que as florestas não "acabam com água", mas ao contrário, "segundo pessoas cuja profissão é estudar isso, e segundo os livros, as florestas têm condições de preservar as águas e não de extingui-las". Nosso interlocutor retrucou: "Mas eu venho observando esse córrego a vida toda e quando isso aqui era lavoura ele era cheio, agora com a floresta a água minguou". Tentamos ampliar sua noção sobre as mudanças climáticas globais e escassez de águas, porém nosso interlocutor foi irredutível: "O problema seu é que você acredita em livro, tem muita bobagem. Me diz uma coisa, esse profissional que você falou, o que escreveu no livro, ele já veio aqui?". Dissemos que não, mas que ele esteve em outros córregos. "Então como ele pode saber deste córrego mais do que eu, que nasci aqui?”. Dissemos que os córregos são semelhantes e que passam por processos semelhantes. "Mas desse córrego aqui ele não sabe. Quando está desmatado tem muita água, mas quando tem floresta, as árvores bebem a água". Alguns dias depois, durante uma seca, esse vizinho que utiliza a mesma nascente que abastece nossas casas nos disse: "Pode ficar tranqüila que as águas agora vão voltar. Já matei as árvores em volta da nascente que estavam bebendo nossa água! Não tem nem graça, as árvores todas bebendo água e nós passando sede!".

Vemos neste exemplo a importância das evidências concretas para a construção do conhecimento em grupos não submetidos à escolarização, tal como descrito na Rússia rural, por Luria ${ }^{14}$. Nossa dificuldade de influenciar as representações do ambiente e da saúde, e as práticas associadas se deu por falta de evidências concretas do saber técnico a ponto de permitir sua integração ao senso comum.

A complexidade dos desafios que se apresentam requer criatividade e a superação do vício no discurso científico encerrado em si mesmo, para a constituição de redes interdisciplinares de pensamento, centradas em problemas concretos, específicos e localizados geograficamente, de modo a produzir efeitos visíveis, tangíveis que aumentem a credibilidade mútua entre técnicos e comunidades rurais. Isso requer muita dedicação e despojamento das verdades acabadas, sejam as do agricultor na beira do rio, as do educador ou técnico em situação de intervenção, "portador das boas novas da ciência", ou a dos teóricos e gestores de gabinete.

\section{A multiplicidade de informações e as estratégias defensivas contra elas (e não só contra as endemias)}

Outro debate relevante na compreensão das relações entre saber sanitário e senso comum sanitário em comunidades rurais agrícolas, diz respeito à apropriação e aplicabilidade das múltiplas informações em oferta. Ainda que os agricultores tenham demonstrado pouco acesso e interesse pelo turbilhão de informações da mídia televisiva, impressa e eletrônica de nossos dias, constatamos pelas entrevistas e pela permanên- 
cia contínua nas localidades rurais, que o aporte de informações sobre saúde se dá em blocos de informação bastante compactos, verdadeiros pacotes temáticos, compilados pelos técnicos e gestores justamente para fazer frente às grandes distâncias envolvidas e ao pouco investimento em intervenções nas localidades rurais, que se dão em reuniões e palestras esporádicas. As iniciativas, por vezes, incluem a distribuição de materiais impressos, raramente avaliados em sua utilidade para tais grupos 15 .

O volume de informações específicas sobre doenças infecciosas é cada vez maior em razão do crescimento exponencial do conhecimento científico. Os serviços de saúde locais são bombardeados por novos conhecimentos desconexos e se apressam em repassá-los, com pouco exercício crítico sobre os significados que possam vir a ser por eles produzidos, ou sobre os constrangimentos para sua aplicação prática na vida local. Evidenciamos ainda nos serviços de saúde locais de muitas comunidades uma demanda, uma ansiedade por constante atualização. Essa demanda é um sintoma de que aquilo que é considerado como correto, legítimo e verdadeiro para a saúde local vem de fora da comunidade. Sintoma da correria pelo saber sanitário em detrimento do saber local, e do imenso trabalho ainda por ser feito, junto ao senso comum sanitário.

Neste ponto de nossa reflexão é preciso esclarecer que não estamos a defender o obscurantismo ou propondo que se tornem desatualizados ou obsoletos os conhecimentos no nível local. Estamos intencionando, isto sim, que essa atualização leve em conta parâmetros locais e possibilidades locais de atualização e de aplicação sensível deste conhecimento, que não pode ser simplesmente transposto linearmente de outros contextos.

Em relação às técnicas médicas, essa expectativa de que uma transposição linear de conhecimentos surta efeitos é bastante evidente. A informação é concebida como medicamento. Assim como só os especialistas sabem qual a composição química melhor para administrar ao leigo, também julgam estar mais aptos a selecionar as informações úteis ao outro 15,16. Isso mantém o conhecimento, de algum modo, hermético, fragmentado e difuso, sem maiores possibilidades de servir ao homem em sua vida cotidiana.

Mas como superar essa exacerbação do etnocentrismo e da autonomia do saber científico em relação ao saber da experiência? Como corrigir uma tal assimetria nas nossas propostas e práticas? Como motivar estudantes a não se contentarem com a perspectiva unilateral do saber técnico, quando ele se avoluma, soterrando o campo da experiência?
Pensamos ser útil o conhecimento das conseqüências da avalanche de dados descontextualizados no universo da experiência. Uma delas é a geração de "mitos" em lugar da elucidação de eventos ecológicos e biológicos relacionados com as doenças infecciosas. Para Alves 17, o perigo da ciência quando se converte em mito é inibir o pensamento, como se alguém estivesse pensando no lugar das pessoas, e assim elas se eximem da atividade de pensamento para simplesmente fazer o que os cientistas "mandam".

Em estudos anteriores focalizamos a interferência dos mitos gerados por informações descontextualizadas sobre a etiologia da esquistossomose 7 , sobre fossas sanitárias 8 ou sobre 0 uso de medicamentos 12. Para o momento, resta esclarecer que nas entrevistas sobre transmissão da esquistossomose nas áreas endêmicas nas quais trabalhamos, o aspecto mais recorrente foi uma multiplicidade de formas de transmissão da doença relatada pelos moradores.

Como evento ecológico complexo, a esquistossomose pode ser contraída em uma ampla gama de situações e de atividades cotidianas que implicam risco de infecção. Banhar-se nos rios por lazer ou durante a lavagem de roupas, plantar a espécie de arroz que cresce em charcos, retirar areia dos rios para comercialização (alternativa de geração de renda rural com a crescente demanda de areia para a construção civil), ou transitar em charcos e áreas alagadas, o que freqüentemente se faz necessário nos trajetos diários dos moradores para a escola, para a casa dos vizinhos, para igreja e para o trabalho. Em muitas localidades que visitamos, ocorre ainda a contaminação no banho tomado na própria residência, e chegamos a encontrar relatos em que os chuveiros das casas ficavam obstruídos e tinham que ser periodicamente removidos para retirada do excesso de caramujos que impediam a passagem da água pelos orifícios!

Num tal quadro de exposição à infecção, os entrevistados para responder às questões: " $\mathrm{Co}$ mo se pega esquistossomose?", e "O que fazer para evitar a esquistossomose?”, discorriam sobre um enorme rosário de proibições e restrições que desafiavam o bom senso (senso comum), visto que incluíam restrições às atividades cotidianas mais básicas, que mantêm a vida em andamento: não trabalhar, não ir à escola, não tomar banho, não sair de casa etc.

Complicando um pouco mais esse quadro, entra o nosso tema em questão, a saber, o da multiplicidade de informações técnico-científicas, em pacotes descontextualizados, e por intermédio de inúmeras fontes na atualidade. As informações sobre todas as doenças infecciosas geralmente são oferecidas em bloco. Uma 
mesma visita ou manual técnico é utilizado para falar da doença de chagas, da leishmaniose e, sobretudo, das outras verminoses junto com a esquistossomose. Toda a comunicação seguindo um padrão lógico familiar para a ciência, mas não para seu público rural, que não dispõe de elementos para fazer distinções, por exemplo, entre vírus, vermes, bactérias, larvas de insetos, ou até mesmos "filhotes de moluscos", que, como vimos em estudo, anterior são hegemonicamente tidos como o próprio agente etiológico da esquistossomose 7 .

Como tantas outras verminoses se transmitem pela ingestão de água, essa idéia acaba sendo incluída também para a esquistossomose, quando estão em oferta tantas mensagens sobre os diferentes ciclos e mecanismos de transmissão de doenças. Parece bastante razoável ainda, do ponto de vista de nossos entrevistados que, se um verme (ou o que seja) tenha a capacidade de penetração por minúsculos poros da pele, também possa passar pelo enorme orifício que é a boca. Neste caso, a resposta à questão "como evitar a esquistossomose", em todas as áreas onde estivemos, incluía no rol de proibições e restrições, "não ingerir a água não tratada", o que em muitas residências significaria dizer: "não beber água”.

Os fundamentos para os processos de transmissão de doenças infecciosas delineados pela ciência permanecem enigmáticos até mesmo para públicos com bom nível de escolaridade, especialmente frente ao crescente número de novos dados e descobertas. Como afirma Geertz 3 , o homem comum não vê tais informações como parte de uma teoria científica articulada. A adoção dos comportamentos preventivos quando ocorre, dá-se por meio do argumento da autoridade e, apenas raramente, por apresentar consistência lógica para as populações, a não ser quando co-incidem com a sabedoria do "bom senso".

Mas se nos voltarmos para a lógica do senso comum, restrições do tipo, "não andar", "não sair", "não trabalhar", "não tomar banho" e "não beber água”, tornam-se dramáticas. O esforço para o cumprimento das prescrições de comportamentos preventivos à esquistossomose reforça uma sensação de incerteza e de precariedade, fruto de condições concretas de privação já vividas nas localidades. Tal como descrito em populações rurais do México 18, identificamos em nossas comunidades uma relação extremamente ambígua com prescrições médicas e com diagnósticos, que acaba por reforçar tal sensação de incerteza.

Um exemplo contundente foi o de uma entrevistada que procurava compreender de que forma se contaminou: “Logo eu! Que ando calçada, corto as unhas, lavo as mãos toda hora, só bebo água filtrada, falo com os alunos sobre saneamento básico".

Em outro depoimento, uma senhora explicava que, por mais que filtrasse a água de sua casa, não permanecia em casa o dia todo e precisava beber água nos locais aonde ia. Na grande maioria dos depoimentos que colhemos em diferentes áreas rurais, o fato de tudo e qualquer coisa transmitir esquistossomose leva a uma conclusão bastante lógica: se tudo é proibido, nada mais se pode fazer, não existe modo de evitar essa doença e, portanto, tudo volta a ser permitido. De todo modo, a vida não pára.

Já sabíamos há algum tempo que a transferência linear de informação sobre as doenças infecciosas não é suficiente para mobilizar comportamentos preventivos conforme desejava a educação funcionalista, mas apenas recentemente passamos a compreender que essa própria transferência de informações pode, inclusive, ter conseqüências inversas, adversas, levando à paralisação dos esforços preventivos.

Quanto mais conhecimentos novos se agregam, descontextualizados das práticas sociais locais e das condições concretas de existência, maior a impressão de que nada pode ser feito, reforçando uma tendência a se atribuir um caráter aleatório às doenças, como fatalidade ou fenômeno acidental. $\mathrm{Ou}$ a recorrer a outros sistemas explicativos para elas.

Entretanto, identificamos estratégias coletivas para lidar com situações de risco para a saúde. Entre moradores de áreas endêmicas de esquistossomose, onde o risco de contaminação foi banalizado e todos se encontram contraindo regularmente esquistossomose, observa-se a tendência a se deslocar a noção de risco, localizando-o apenas naqueles indivíduos que não tomam remédios para "desbastar a quantidade de vermes". Esses sim, no olhar dos moradores de áreas endêmicas, correm o risco de ter o "verme brabo mesmo", ou seja, de desenvolverem quadros mais graves da doença. Já os que se contaminam todos os dias, neste caso, passam a estar fora de perigo ${ }^{7}$.

Também identificamos como estratégia coletiva uma seleção, pelo senso comum, daqueles comportamentos considerados preventivos ou saudáveis que podem ser levados a cabo, elegendo-os como os comportamentos corretos para evitar a esquistossomose, e relegando a um segundo plano os que são de difícil consecução. Como nos alerta Geertz 3 (p. 122), ao realizar sua epistemologia do "senso comum": "os homens tampam os orificios das barragens de suas crenças mais necessárias, com o primeiro tipo de barro 
que encontrem". Nesse sentido, o saneamento e o contato com águas contaminadas da região são menos valorizados no discurso dos moradores do que o "cortar unhas, beber água filtrada, lavar as mãos" que são comportamentos viáveis, de fácil execução.

Para Geertz 3 , enquanto a religião baseia seus argumentos na revelação, a ciência na metodologia, e a ideologia na paixão moral, os argumentos provenientes do senso comum não se baseiam em coisa alguma, a não ser na vida como um todo. A vivência de mundo é sua autoridade. Para esse autor, analisar a estrutura de pensamento do senso comum requer que se reformule uma distinção esquecida entre a mera apreensão da realidade e aquela "sabedoria coloquial”, com pés no chão, que julga ou avalia essa realidade.

As áreas onde a malária e outras doenças transmissíveis por mosquitos são endêmicas fornecem outro exemplo de como as crenças do senso comum das populações expostas, consideradas pela ciência como "conhecimentos errôneos", podem na realidade ser bastante estratégicas. As atividades extrativistas e agrícolas expõem os homens à picada dos mosquitos transmissores durante o dia, durante seu trabalho, base da subsistência de suas famílias e de sua identidade como provedores. Ainda que à noite utilizem mosquiteiros, e que tenham suas casas borrifadas com inseticidas, é impossível vestir-se diariamente com um mosquiteiro para trabalhar ou borrifar a floresta inteira. Nesses grupos, verifica-se a estratégia coletiva de negação da picada do mosquito como única forma de transmissão. Outras formas de se contrair malária são agregadas e mantidas como modelo explicativo alternativo, tais como a ingestão de determinados tipos de alimento.

O que se observa é um esforço legítimo de preservar o ethos masculino de provedor da família, que se torna profundamente ameaçado com a versão científica da transmissão da malária. Nesse caso a população procura defender-se não só da malária, mas também dos conhecimentos científicos sobre tal doença que julgam prejudiciais.

Segundo Oliveira \& Valla 19 (p. 86-7), estudan-


fácil afirmar que a população cria situações de riscos porque não tem informações. No entanto, as soluções que criam, muitas vezes são as únicas possíveis diante da realidade. O 'principio de realidade' fala mais alto (...) é melhor arriscar tendo como referência o conhecimento construído pela experiência (...) do que apostar apenas nas soluções técnicas indicadas por um 'agente estranho', que sequer valoriza sua experiência de vida".

\section{Considerações finais - tecnologias exógenas como símbolo de progresso}

Segundo Escobar 20, o desafio que se coloca ao conhecimento científico na atualidade é favorecer a defesa de modelos de vida social e natural baseados no lugar, contra o efeito de deslocalização da economia/cultura global; e contra a reestruturação em curso dos mundos locais pelo capital e pela cultura globais. Para o autor, os movimentos sociais têm avançado bem mais do que a academia nessa direção.

Para Santos, a ciência tanto pode ser regulatória quanto emancipatória 1 . As iniciativas que valorizam a capacidade analítica, os conhecimentos e a destreza intelectual do cidadão comum apontam caminhos emancipatórios; pois nenhuma justiça social global será possível sem uma justiça cognitiva global 1,20.

Por outro lado, em sua face regulatória, a ciência, além de excluir outras formas de conhecimento, tende a alimentar o uso e substituição de tecnologias de complexidade crescente, em última análise, atendendo a interesses de setores poderosos da sociedade propondo, por vezes, modelos humana e ecologicamente irracionais.

Coletamos, ao longo da última década, exemplos desta adoção irracional de modelos "científicos" que desenraizam outros baseados no saber local. Um, entre tantos, é o do Ipê roxo, planta que tem princípio ativo eficaz contra o câncer, que já não é mais usada em chás caseiros, mas passa a ser comprada - inclusive na população rural, pelos que têm poder aquisitivo - em fórmulas caríssimas da Nature Sunshine ou da Herbalife (marcas importadas de produtos naturais) enquanto a espécie está desaparecendo das localidades.

Vimos no presente trabalho que, a multiplicidade de conhecimentos científicos descontextualizados não é de fácil apropriação; entretanto, os produtos dela resultantes são rapidamente apropriados. Em trabalhos anteriores identificamos essa tendência em relação às tecnologias médicas e agrícolas 7,8,10,12. É preciso investigar melhor a questão do consumo em grupos rurais, mas a princípio, nossa hipótese é a de que os produtos "cientificamente testados", para além de seus efeitos quimioterápicos, exercem grande fascínio como símbolo inequívoco de progresso e de mudança de status social.

A autonomia local, que vem sendo perdida com a globalização, cria situações como a descrita em Uchôa et al. 16, vale dizer, um lote de pomadas ginecológicas vencidas vinha sendo usado em uma comunidade agrícola para todos os tipos de cortes e ferimentos! Com o status de remédio de farmácia, ela era distribuída no posto, 
gerando lesões de pele nas pessoas, que abdicaram do uso tradicional de plantas cicatrizantes como saião ou a erva-de-bicho, que cresciam nas redondezas.

Em outra ocasião, quando perguntávamos aos moradores de áreas rurais por que motivo não faziam uso, por exemplo, de ervas calmantes para substituir o Valium ou Lexotan (Roche, Brasil), uma resposta em particular nos surpreendeu: ao fazerem chás de ervas, nunca saberiam quantos miligramas da substância estariam ingerindo e por isso os chás poderiam fazer mal à saúde. Já o Valium tinha o aval de um laboratório e tinha escrito na caixa a dosagem. Ocorria na região, entretanto, um quadro de intoxicações crônicas por tais medicamentos comprados em farmácias sem receita médica 12 .

Como contraponto a esse comportamento, observamos, em comunidades rurais de Nova Friburgo, uma tendência a modificar os nomes vulgares das plantas medicinais por nomes de medicamentos vendidos em farmácias. Assim, muitas plantas nos foram apresentadas como "um pé de Novalgina", de "Gelol" ou de "balinha Halls". São plantas com efeitos considerados similares, aos de tais produtos. Essa iniciativa representa um esforço de aproximação ao saber "oficial" e ao mesmo tempo de validação e de aceitação do saber local. Em certo sentido é uma estratégia de resistência, pois em lugar de descartar o saber rural, tenta agregar-lhe valor, ainda que de modo inusitado.

Nossas entrevistas em diferentes áreas rurais do Brasil revelaram que os profissionais de saúde que atuam no campo em serviços e programas descentralizados, mesmo que não reconheçam a si mesmos como educadores, têm forte influência na construção do sentido da saúde e da doença para as populações rurais, mais até do que as palestras formais dadas por educadores, que se apóiam apenas na expressão verbal 7 .
É preciso que reconheçam o modo como suas práticas e atitudes influenciam seus "públicos" para desenvolver um posicionamento crítico em relação ao seu inevitável papel de mediadores entre ciência e senso comum sanitário. Se os profissionais se mostram pouco interessados nos conhecimentos e experiência locais e desvalorizam as contribuições rurais em saúde, convidam as populações a desvalorizar também sua própria contribuição, participação e possibilidades. Assim, fortalecem a face regulatória da ciência e abandonam seu potencial emancipatório 1,20.

Podemos concluir que o mito de que o saber científico é o único capaz de oferecer soluções para todos os problemas humanos 4 apresenta em áreas rurais efeitos dramáticos de auto-abandono das comunidades aos interesses do capital industrial.

Finalmente, mais do que gerar esquemas educativos e investigativos vagos e gerais, como reação automática ao abismo entre teoria e prática, é necessário integrar o saber teórico dos meios acadêmicos ao saber do senso comum das comunidades, em soluções criativas, no nível prático-concreto, aos graves problemas sócio-sanitários da atualidade. Para isso entram em foco, nos anos recentes, análises refinadas de sistemas culturais, simbólicos e imaginários que, como dissemos anteriormente, por muito tempo foram consideradas apenas anedóticas e marginais ao conhecimento científico.

Se por um lado, trabalhar com relatos sobre a forma como um grupo interpreta sua experiência nos distancia de um estilo padrão de demonstração científica ${ }^{3}$, por outro contribui para modificar a posição dos refletores, estimulando os programas de prevenção e controle de doenças infecciosas a buscarem novos ângulos para uma construção partilhada de conhecimentos favoráveis à saúde e à cidadania nos contextos locais da América Latina. 


\section{Resumo}

Com base em experiências prévias de dois projetos de pesquisa sobre esquistossomose em populações rurais, $o$ artigo debate as relações entre o saber sanitário e o senso comum sanitário em comunidades agrícolas. $O$ artigo refere-se a fatores que interferem com a noção de participação destes grupos em programas exógenos, bem como com a apropriação, validação e aplicabilidades das múltiplas informações científicas em oferta em tais programas. A multiplicidade de informações que aportam no nível local, como uma das facetas marcantes da globalização, agrega de forma acrítica conhecimentos científicos descontextualizados, aumentando a sensação de incerteza nas comunidades $e$ a tendência a se atribuir um caráter aleatório às doenças. Por outro lado, o consumo de tecnologias médicas é bastante valorizado e compreendido como símbolo inequívoco de progresso. Discute-se a importância da atitude dos profissionais da saúde como aliados na valorização do senso comum e da experiência empírica das populações rurais, que beneficiem a incorporação do saber técnico de utilidade pública sem prejuízo do patrimônio cultural que está na base da identidade e da saúde destes grupos.

População Rural; Comunicação em Saúde; Percepção Pública da Ciência

\section{Referências}

1. Bizzo MLG. Difusão científica, comunicação e saúde. Cad Saúde Pública 2002; 18:307-14.

2. Santos BS. Um discurso sobre a ciência. 13a Ed São Paulo: Editora Hucitec; 1985.

3. Geertz C. O saber local. Novos ensaios em antropologia interpretativa. 5a Ed. Petrópolis: Editora Vozes; 1997.

4. Chauí M. Contingência e necessidade. In: Novaes A, organizador. A crise da razão. São Paulo: Companhia das Letras; 1996. p. 19-26.

5. Francelin MM. Ciência, senso comum e revoluções científicas: ressonâncias e paradoxos. Cienc Inf 2004; 33:26-34.

6. Toledo VM. Tres problemas em el estúdio de la apropriación de los recursos naturales y sus repercussiones en la educación In: Leff E, organizador. Ciencias sociales y formación ambiental. Barcelona: Gedisa; 1994. p. 157-78.

7. Rozemberg B. Representação social de eventos somáticos ligados à esquistossomose. Cad Saúde Pública 1994; 10:30-46.

8. Rozemberg B. Saneamento rural em áreas endêmicas de esquistossomose: experiência e aprendizagem. Ciênc Saúde Coletiva 1998; 3:125-41.

9. Gomes AA, Rozemberg B. Condições de vida e saúde mental na zona rural de Nova Friburgo. Psicol Ciênc Prof 2000; 20:16-29.

10. Levigard YE, Rozemberg B. A interpretação dos profissionais de saúde acerca das queixas de "nervos” no meio rural: uma aproximação ao problema das intoxicações por agrotóxicos. Cad Saúde Pública 2004; 20:1515-24.

11. Rozemberg B. Conflitos entre interesses agrícolas e ambientalistas nas comunidades rurais de Nova Friburgo, RJ. In: Minayo MCS, organizador. Críticas e atuantes: ciências sociais e saúde na América Latina. Rio de Janeiro: Editora Fiocruz; 2005. p. 531-48.
12. Rozemberg B. O consumo de calmantes e o problema de nervos entre lavradores. Rev Saúde Pública 1994; 28:300-8.

13. Fausto Neto A. Percepções acerca dos campos da saúde e da comunicação. In: Pitta AMR, organizadora. Saúde \& comunicação: visibilidades e silêncios. São Paulo: Editora Hucitec; 1995. p. 267-93.

14. Luria AR. Desenvolvimento cognitivo: seus fundamentos culturais e sociais. São Paulo: Editora Ícone; 1990.

15. Vasconcellos-Silva PR, Riviera JU, Rozemberg B. Próteses de comunicação e alinhamento comportamental: uma revisão da literatura sobre impressos hospitalares. Rev Saúde Pública 2003; 37: 531-42.

16. Uchôa E, Rozemberg B, Porto MFS. Entre a fragmentação e a integração: saúde e qualidade de vida de grupos populacionais específicos. Inf Epidemiol SUS 2003; 11:7-20.

17. Alves R. Filosofia da ciência: introdução ao jogo e suas regras. 2a Ed. São Paulo: Edições Loyola; 2000.

18. Castro-Peres R. La vida en la adversidad: el significado de la salud y la reproducción en la pobreza. Cuernavaca: Centro de Investigações Interdisciplinares, Universidad Nacional Autónoma de México; 2000.

19. Oliveira RM, Valla VV. As condições e as experiências de vida de grupos populares no Rio de Janeiro: repensando a mobilização popular no controle do dengue. Cad Saúde Pública 2001; 17 Suppl:77-88.

20. Escobar A. Atores, redes e novos produtores de conhecimento: os movimentos sociais e a transição paradigmática nas ciências. In: Santos BS, organizador. Conhecimento prudente para uma vida decente. São Paulo: Cortez Editora; 2004. p. 639-66.

\footnotetext{
Recebido em 09/Nov/2005

Versão final reapresentada em 19/Mai/2006

Aprovado em 22/Mai/2006
} 